\section{ambient SCIENCE \\ Vol. 05(Sp1):46-49 \\ Year 2018}

\title{
An Assessment of Admission and Discharge Processes to Improve Patient Satisfaction in Peymaniyeh Hospital of Jahrom, Iran
}

\section{Esmail Rayat Dost', Maryam Adnani', Tahere Abdian', Fajriyeh Zahedinia ${ }^{2}$, Seyed Hamed Hojati ${ }^{3}$, Navid Kalani ${ }^{4}$, Samaneh Abiri ${ }^{\text {1* }}$}

'Department of Emergency Medicine, Jahrom University of Medical Sciences, Jahrom, Iran.

${ }^{2}$ Department of Nursing, Peymaniyeh Hospital, Jahrom University of Medical Sciences, Jahrom, Iran.

${ }^{3}$ Student Research Committee, Jahrom University of Medical Sciences, Jahrom, Iran.

${ }^{4}$ Research center for social Determinants of Health, Jahrom University of Medical Sciences, Jahrom, Iran.

Study Area:Jahrom, Iran

Coordinates: $28^{\circ} 30^{\prime} \mathrm{oo}^{\prime \prime N}$; $53^{\circ} 33^{\prime} 38^{\prime \prime} \mathrm{E}$

Key words: Hospitality, Patient satisfaction, nursing care, Medical treatment.

This project was approved by Jahrom University of Medical Sciences in 2017 with the ethic code of IR.JUMS.REC.1396.064

\section{Introduction:}

Patients could be the most important source to gather the relevant information and assessing the quality of health services provided and finally achievement of goals of the healthcare system (Zolfaghari et al., 2005). The main goal of a health system is societal health, which can be achieved by the offering of appropriate services while controlling and evaluating health services. Assessment of patient satisfaction is an important factor in the monitoring and evaluation of health services (Faridpour, 2015, Zahednezhad, 2012). In general, any significant change or decrease in performance quality necessitates a physical, psychological and social readjustment of an individual alongwith their family members. As a result, most of the patients worry about constraints imposed by diseases that make changes in their lifestyle. Therefore, it is not advisable to leave the patients and their family members alone. The hospital is a safe and secure place for the patients as long as they remain hospitalized. They should be discharged from the hospital as soon as there is no more need for hospital

\section{Abstract}

Assessment of patient satisfaction can be a potential source of information to identify the crucial problems for designing suitable plans to serve healthcare properly. Therefore, the present study aimed to access the admission and discharge processes done to improve patient satisfaction via a descriptive, cross-sectional study conducted on 246 patients as subjects admitted to Peymaniyeh Hospital in Jahrom. Data on the demographic status and standardized admission-to-discharge survey report were collected for improving patient satisfaction were completed by the patients. Mean age of the participants in this study was $40 \pm 19$.6. Analysis of findings showed that overall satisfaction rate of patients was higher than average. No signif icant difference was found in average satisfaction rates in terms of gender, the respondent, the reason for visiting the hospital (the ward the patients were referred to), occupation, reason for selecting this hospital and length of hospitalization. However, there was a significant difference in satisfaction rates of the patients in terms of age, education, place of residence, lack of free beds. The results showed higher than average overall satisfaction of patients with healthcare services regarding admissionto-discharge processes.

care. Perhaps the patients often feel threatened and afraid of the term discharge and which must be avoided. The patients should be relieved of being discharged from the hospital and they should enjoy being nearer to their respective families and regaining the health. Further, they also remain under stress regarding their future as soon as they hear that they would be shortly discharged from the hospital. The patients are worried about being discharged from the hospital. They think that how they can manage themselves in a normal way while returning back to their families (Duogas, 1992). If hospitalization and discharge procedures remain unsatisfactory, the overall quality of service and patient safety would remain questionable. Various studies have shown that one out of five patients experiences unwanted accidents after discharge from the hospitals Vanaki \& Habibipour, 2008). Sixty-two percent of these accidents can be avoided (Sarvandi \& Shahroodi, 2016). The likelihood of hospitalization or subsequent referral of the patient of the emergency department increase in case of unsatisfactory discharge process (Hesselink et al.,2012). Therefore, the discharge process is one of the most

*Corresponding Author: samaneh.abiri@gmail.com 
important and common components of the healthcare system in many countries. Reduced length of hospitalization, costs, referral and mortality rates, continuous care in society, improved mental health of the patient, satisfaction with care team members, improved disease, and comfortable and safe transfer to home would be the goals of the discharge process (Shepperd et al.,2013). Since patient satisfaction is a criterion of quality of service delivery at various interpersonal and organizational levels, patient satisfaction assessment can be an important source of information to identify potential problems and appropriate programs in health service delivery (Kurpas \& Steciwko, 2005). Thus the patient satisfaction assessment is necessary for improving the quality of health care. Hospital environments, services, healthcare services, hotel services, food, admission and etc. are effective factors which regulates the patient satisfaction which must be assessed. Consequently, the assessment of patient satisfaction can be used to analyse the hospitals' performance (Sadaghyani, 2005). Given the importance of admission-to-discharge processes and its relevant effect on patient satisfaction in health care system, the present study aimed to investigate admission and discharge processes in order to improve patient satisfaction in Peymaniyeh Hospital, Jahrom, Iran.

\section{Methodology:}

We conducted a descriptive, cross-sectional study. The protocol researcher was introduced and its respective goals were properly explained to the relevant unit. Further, we processes to improve patient satisfaction in Peymaniyeh Hospital in Jahrom in the year 2017. The statistical population consisted of all patients admitted to Peymaniyeh Hospital in Jahrom. The stratified sampling method was used to select 246 patients from different wards. They were randomly selected from each ward. The inclusion criteria were the patients visiting Peymaniyeh Hospital and having proper awareness about the subject whereas the exclusion criteria were lack of cooperation and dissatisfaction to participate in the study and provided incomplete answers for questionnaires. The questionnaires were distributed to the selected patients in different shifts and days at every three days gaps and collected after completion. We visited the hospital every three days to collect the information on new admissions. The first part of the questionnaire covered personal information and patients' history and the second part consisted of a standardized admission-to-discharge survey to improve regarding the admission, food, medical care, nursing, diagnostic and treatment, food, accounting, and discharge services as well as Patients' Rights Charter. The patient satisfaction score ranged from zero to five. Items of the questionnaire were scored based on a five-point Likert scale (not mattered (no score) $=0$ ), very low $=1$, low $=2$, attempted to investigate the admission and discharge patient satisfaction. Items of the questionnaire were

somewhat $=3$, high $=4$ and very high $=5$ ). Earlier, the questionnaire was studied successfully by Jannati et al. (2014) and Omidvari et al. (2008). Reliability of the questionnaire was assessed using Cronbach's alpha (93\%) (Montazeri et al., 2008; Janati et al., 2016). The research hypotheses were investigated. The t-test was used to compare means of different components of satisfaction. Independent t-test or one-way ANOVA was used to examine the difference between satisfaction rates with respect to research variables. SPSS v.24 and Excel were used for data analysis. The significance level was considered as 0.05 for all statistical tests.

\section{Results:}

The number of participants was 246. Frequency and frequency percent of the total participated (246) patients with respect to demographic variables are presented in Table-1. In our study, $130(54.2 \%)$ were males and 110 (45.8\%) were females. (mean: $40 \pm 19.6)$. Out of 238 responses to a reason for visiting the hospital, 106 patients $(44.5 \%)$ visited for hospitalization, $54(22.7 \%)$ were outpatients, 21 patients $(8.8 \%)$ visited the hospital for clinical problems, 1 patient (o.4\%) for Para clinical reason and 56 patients $(23.5 \%)$ for emergency cases.

Table 1: Frequency and frequency percent of respondents with respect to demographic variables

\begin{tabular}{|c|c|c|}
\hline \multicolumn{2}{|l|}{ Characteristic } & Number (\%) \\
\hline \multirow[t]{2}{*}{$\checkmark$ Respondent } & Patient & $112(45 \cdot 5)$ \\
\hline & Patient accompanier & $134(54 \cdot 5)$ \\
\hline \multirow{5}{*}{$\begin{array}{l}\checkmark \text { Reason for visiting } \\
\text { the hospital }\end{array}$} & Hospitalization & $106(44 \cdot 5)$ \\
\hline & Outpatient & $54(22.7)$ \\
\hline & Clinic & $21(8.8)$ \\
\hline & Para clinic & $1(0.4)$ \\
\hline & Emergency & $56(23 \cdot 5)$ \\
\hline \multirow[t]{5}{*}{$\checkmark$ Age } & $=20$ & $27(11.2)$ \\
\hline & $21<$ age $<35$ & $98(40.7)$ \\
\hline & $36<$ age $<50$ & $54(22.4)$ \\
\hline & $51<$ age $<65$ & $31(12.9)$ \\
\hline & $>65$ & $31(12.9)$ \\
\hline \multirow[t]{2}{*}{$\checkmark$ Gender } & Male & $130(54.2)$ \\
\hline & Female & $110(45.8)$ \\
\hline \multirow[t]{7}{*}{$\checkmark$ Occupation } & Unemployed & $31(12.8)$ \\
\hline & Labor & $35(14.4)$ \\
\hline & Employee & $26(10.7)$ \\
\hline & Freelancer & $50(20.6)$ \\
\hline & Housekeeper & $70(28.8)$ \\
\hline & Retired & $6(2.5)$ \\
\hline & Others & $23(9.5)$ \\
\hline \multirow[t]{4}{*}{$\checkmark$ Education } & Illiterate & $38(18.2)$ \\
\hline & Writing and reading & $60(28.7)$ \\
\hline & Undergraduate & $63(30.1)$ \\
\hline & Academic education & $48(23)$ \\
\hline \multirow[t]{2}{*}{$\checkmark$ Place of residence } & Local & $145(58.5)$ \\
\hline & Not local & $103(41.5)$ \\
\hline$\checkmark$ Length of & 1 day & $51(32.1)$ \\
\hline \multirow[t]{2}{*}{ hospitalization } & 2 days & $37(23 \cdot 3)$ \\
\hline & 3 days & 30(18.9) \\
\hline
\end{tabular}




\begin{tabular}{lll} 
& 4 days & $12(7.5)$ \\
& 5 days & $11(6.9)$ \\
& $=6$ days & $18(11.3)$ \\
$\checkmark$ Reason for selecting & Nearer to us & $106(46.7)$ \\
this hospital & Recommended by & $18(7.9)$ \\
& acquaintances & \\
& Satisfactory services & $13(5.7)$ \\
& in previous visits & \\
& Low cost & \\
& Expert employees and & \\
& facilities in this center & $35(15.4)$ \\
& Referred to this center $14(6.2)$ \\
& from other centers & \\
& Other reasons & $14(6.2)$ \\
& Yes & $63(25.5)$ \\
$\checkmark$ No more free beds & No & $155(62.8)$ \\
& Not mattered & $26(10.5)$ \\
\hline
\end{tabular}

Table 2: Obtained scores against each item from the patients

Item Questions to respond Mean+SD

\# (number of patients responded)

27 Respecting privacy of patients (232)

$3.75 \pm 1.37$

15 How the nurses treat and handle patients (240)

$3.75+1.21$

35 Having medications \& medical equipment (225)

18 Orderly nursing care (240)

4 Speed of filing (251)

10 Timely delivery of medical services (229)

2 Treatment \& Guidence from the guards and information center to the patients (253)

1 Guidance signs and symbols in the hospital (254) 3.72+1.17

16 Timely delivery of nursing care services (238) $\quad 3.71 \pm 1.34$

17 Description of nurses on medical services done $3.70 \pm 1.27$ for the patients (238)

26 Observing religious regulations in sampling and imaging (227)

$3.70 \pm 1.36$

3 Treatment \& Guidence from admission staff (254) $3.69 \pm 1.36$

12 Physician spend enough time to examine (237) $3.69 \pm 1.25$

36 Availability of necessary medical equipment (226)3.67 \pm 1.25

13 Treatment from the physicians (242) 3.66 \pm 1.29

19 Nursing skills viz.,. injection, dressing etc. (238) 3.64 \pm 1.34

14 Description of physicians on medical measures $3.62 \pm 1.28$ done for the patients (239)

28 Health state of the hospital (236)

40 Speed of carrying out discharge tasks (225)

11 Presence of physicians as necessary (228)

21 Coordination and collaboration between the medical and nursing staff (234)

$3.62 \pm 1.29$

$3.61+1.33$

$3 \cdot 57 \pm 1.29$

$3 \cdot 57 \pm 1.30$

6 Turns in visiting the patients in the hospital (250) $3.57 \pm 1.28$

22 Treatment \& consideration from t other staff (232) 3.56 \pm 1.33

25 Obeying religious regulations in carrying out $3.56 \pm 1.43$ medical procedures (227)

46 Recommending this hospital to others (224)

9 Timely transfer of patient (226)

$3 \cdot 54 \pm 1.43$

$3.53 \pm 1.33$

$3.53 \pm 1.52$

39 Treatment from the staff on discharge (227)

47 Paying services to patients at this hospital (226) $3.53 \pm 1.42$

$\begin{array}{lll}33 & \text { Facilities for accompaniers; chair, food, etc. (229) } & 3.53 \pm 1.35 \\ 29 & \text { Outdoor facilities; greenery, buffet, amenities (229) } & 3.50+1.38\end{array}$

45 Reselection of this hospital in case of disease (222) $3.50 \pm 1.50$

30 Hospital room condition; cleanness, space $\quad 3.44 \pm 1.43$ between beds, temperature, light etc. (226)
5 Speed of transfer to a ward after admission (245) $3 \cdot 43 \pm 1.41$

41 Hospital costs (224) $3.41 \pm 1.40$

34 Quiet and peaceful environment (232) $3.41 \pm 1.33$

24 Laboratory tests (232) $3.38 \pm 1.62$

31 Ward amenities; telephone, TV, etc. (228) 3.30 \pm 1.42

38 Performance of cashier (228) 3.35 \pm 1.61

20 Practical nursing services in carrying out personal $3.34 \pm 1.53$ affairs (240)

23 Imaging tasks (231) $3.32 \pm 1.67$

32 State of sanitary facilities; W.C. toilet, bath (229) $3.31 \pm 1.40$

8 Waiting time for surgery (214) $3.25 \pm 1.65$

42 Quality of served food; flavor, taste, temperature, 3.22 \pm 1.54 amount, clean dishes (220)

7 Waiting time for hospitalization (250) $3.20 \pm 1.40$

43 Visiting days and hours (227) $3.13 \pm 1.59$

37 Guidance of insurance expert (227) $3.06 \pm 1.70$

44 Performance of workers (221) $3.01 \pm 1.73$

Mean + standard deviation of the scores obtained from the respondents and the number of respondents to each item are presented in Table-2. The items were sorted according to the average score of respondents to each item (i.e. satisfaction rate of each item). The satisfaction rate decreases in descending order in the table. Contents of Table-2 also show that the five items with the highest satisfaction rates are respecting the privacy of patients, how nurses treat and consider the patients, availability of medications and medical equipment, orderly nursing care services and speed of filing. The five items with the lowest satisfaction rate were the performance of workers, a guidance of insurance expert, visiting days and hours, waiting time for hospitalization and served food (taste and flavor, temperature, amount and clean dishes).

Table 3: Overall satisfaction and its components and t-test result

\begin{tabular}{|c|c|c|c|}
\hline Satisfaction with & Mean+SD & t-test & $\mathrm{p}$ value \\
\hline Food services & $3.27 \pm 1.49$ & 2.664 & 0.008 \\
\hline Respecting patients' rights charter & $3 \cdot 74 \pm 1.02$ & 10.633 & 0.000 \\
\hline Hotel services & $3 \cdot 57 \pm 0.91$ & 9.200 & 0.000 \\
\hline Admission services & $3.50 \pm 0.97$ & 7.630 & 0.000 \\
\hline Medical services & $3.70 \pm 0.96$ & 10.769 & 0.000 \\
\hline Nursing services & $3.67 \pm 1.07$ & 9.151 & 0.000 \\
\hline Diagnostic and treatment services & $3 \cdot 54 \pm 1.15$ & 6.839 & 0.000 \\
\hline Accounting and discharge services & $3 \cdot 39 \pm 1.16$ & 5.015 & 0.000 \\
\hline Overall satisfaction & $3 \cdot 54 \pm 0.86$ & $9 \cdot 322$ & 0.000 \\
\hline
\end{tabular}

The t-test results showed overall satisfaction and all its components are signif icantly higher than 3 and higher than average. The highest satisfaction rates belonged to medical services, secondary to respecting patients' rights charter. The lowest satisfaction rates belonged to food services, and accounting and discharge services (Table-3)

Statistical analysis of ANOVA showed no significant difference between mean satisfaction rates in terms of gender, the respondent, the reason for visit (visited ward), occupation, the reason for selecting this hospital and the length of hospitalization. But, there was a significant difference between mean satisfaction rates with respect to age, education, place of residence and free beds (Table-4). 
Table 4 : overall mean satisfaction rate with respect to research variables and results of t-test and one-way ANOVA

Parameters: Statistical Test; Statistic value; p-value

Category

$\mathrm{OS}^{*}$

Category

OS*

$\checkmark$ Respondent: t-test; Stat.-0.112; p $\geq 0.911$

Patient $\quad 3.54 \quad$ Patient accompanier 3.52

$\checkmark$ Reason for visiting hospital: ANOVA; Stat.-1.6o1; $\mathbf{p} \geq 0.190$

Hospitalization $\quad 3.6310$ Outpatient 3.5141

$\begin{array}{llll}\text { Clinic } & 3.1664 & \text { Paraclinic* } & 3.2567\end{array}$

Emergency $\quad 3.5766$

$\checkmark$ Age: ANOVA; Stat.-5.205; $\mathbf{p}<0.001$

$\leq 20 \quad 3.4323$

$\begin{array}{llll}>21 \text { to }<35 & 3.2590 & >36 \text { to }<50 & 3.6922 \\ 51<2 g e<65 & 3.9413 & >65 & 3.8062\end{array}$

$\checkmark$ Gender: t-test; Stat.-0.731; p $>0.466$

Male 3.6020 Female

$\checkmark$ Occupation: ANOVA; Stat.-1.265; $\mathbf{p} \geq 0.270$

Unemployed $\quad 3.3183$ Labor

Employee

3.4009 Freelancer

3.7209 Retired

3.3045

Others

$\checkmark$ Education: ANOVA; Stat.-10.596; $\mathbf{p}<\mathbf{0 . 0 0 0 1}$
Illiterate 3.9456 Writing \& read

Illiterate $\quad 3.9456$ Writing \& reading 3.6943

Undergraduate $\quad 3.5646$ Academic education 3.0240

$\checkmark$ Place of residence: $t$-test; Stat.-3.060; $\mathbf{p}<0.003$

Local 3.3843 Not local 3.7481

$\checkmark$ Length of hospitalization: ANOVA; Stat.-2.o82; $\mathbf{p} \geq \mathbf{0 . 0 7 1}$

1 day $\quad 3.5970 \quad 2$ days 3.8506

3 days $\quad 3.8006 \quad 4$ days 3.6473

5 days $\quad 3.9362 \geq 6$ days 3.1650

$\checkmark$ No more free beds: ANOVA; Stat.-6.394; $p<0.002$

$\begin{array}{llll}\text { yes } & 3.2399 \text { no } & 3.7107\end{array}$

No mattered $\quad 3.3535$

$\checkmark$ Reason for selecting the hospital: ANOVA; Stat.-1.595; p>0.151

Nearer to us

Recommended by acquaintances

3.4056

3.4289

Satisfaction with services of the center in earliervisits $\quad 4.1029$

Low cost

3.8178

3.5957

3.2996

Referred to this center from other centers

Others

3.4365

$\mathrm{OS}^{*}$ - Overall mean satisfaction

\section{Discussion:}

According to the World Health Organization, patient satisfaction with provided health service is one of the five quality service delivery factors. Some researchers have also identified this factor as one of the most important determinants of health care quality (Shaw \& Kalo, 2002, González et al.,2005). Therefore, this study was aimed to evaluate the admission and discharge processes to improve patient satisfaction in Peymaniyeh Hospital of Jahrom. Analysis of the findings revealed that the overall mean satisfaction rate of patients was higher than average. Omidvari et al. (2008)'s study was concentrated on five major hospitals of Tehran University of Medical Sciences where they reported that $85.8 \%$ of patients had higher than average satisfaction. Zohur \& Piri (2003) evaluated outpatients in a university hospital and reported acceptable patient satisfaction and Fesharaki et al. (2015) assessed the satisfaction of hospitalized patients and relevant effective factors in a super-specialized hospital in Tehran and reported a high level of overall satisfaction of the patients. Although overall patient satisfaction was higher than average in our study, various other issues are undoubtedly involved in patient satisfaction in different parts of Iran. The results of our study indicated that the highest satisfaction rate belonged to medical services, secondary to respecting patients' rights charter. The lowest satisfaction rate belonged to accounting and discharge services, secondary to food services. Ebrahimnia et al. (2010) investigated the satisfaction rate of patients admitted to military hospitals and showed that the highest satisfaction rate belonged to medical services and the lowest satisfaction rate belonged to amenities. our study, patient satisfaction with medical services was high. Zolfaghari et al. (2005) also reported the rate of satisfaction with medical and nursing services as $60 \%$, which was lower than the satisfaction rate reported in our study. Hekkert et al. (2009) studied 22 educational and public hospitals in the Netherlands and reported that the highest satisfaction rate belonged to the admission process in hospitalized and discharged patients. However, the highest satisfaction rate belonged to respecting patients' rights charter in our study. Lin et al. (2005) designed an experimental discharge program for orthopedic patients and showed that patient satisfaction increased with orderly discharge planning, which increased the quality of care and reduced the length of hospitalization. Horwitz et al. (2013) reported that satisfactory hospitalization and discharge plans in the hospital increase the patient satisfaction with hospital services. Unfortunately, satisfaction with the discharge plan was found to be low in our study, which indicates the necessity of careful planning towards this issue in Peymaniyeh Hospital in Jahrom. Lee et al. (2008) reviewed 1866 patients suffering from myocardial infarction and found a significant relationship between age and patient satisfaction. Hall \& Press (1996) reported that age and gender variables had little effect on satisfaction. In the present study, the highest satisfaction rate belonged to 5165 age group and the lowest satisfaction rate was evidence for the age group of 21-35 but there was no significant difference between gender variable and patient satisfaction. Mahsa et al. (2012) studied the patients visiting Qods Clinic of Tehran Social Security and reported higher satisfaction rate in more educated patients. Sheikhi \& Javadi (2004) found a significant relationship between education of respondents and their satisfaction in Qazvin Medical Education Center of Iran. Satisfaction rate of the patients was found to be significantly decreased in more educated patients in our study. Illiterate patients were highly satisf ied with hospital services and the patients with 
academic education were least satisfied with hospital services. Education seems to increase patient expectations from hospital services. The results of our study showed a significant relationship between lack of free beds and satisfaction. Buckley et al. (2010) reported that the dearth of beds was a problem in hospitals, which lengthens the admission process and delivery in care services.

Concludingly, the overall mean satisfaction of patients waiting for free beds was significantly less than those experiencing no such case in the present study. Therefore, the results of this study showed that overall satisfaction of patients with healthcare process from admission to discharge was higher than average. Therefore, it is necessary to make a fully-organized plan to resolve weakness in the delivery of those services with the least satisfaction rates (food, accounting, and discharge) by paying attention and prioritizing these services in order to deliver more suitable services to the patients.

\section{Acknowledgment:}

This article is a part of research project "Review of admission and discharge processes to improve patient satisfaction in Peymaniyeh Hospital in Jahrom in 2017", sponsored by Jahrom University of Medical Sciences. We are thankful to the Clinical Dev. Res. Dept in Edu. Res. \& treatment center of University of Medical Sciences, Jahrom that supplied the necessary facilities.

\section{References:}

Buckley, B.J., Castillo, E.M., Killeen, J.P., Guss, D.A. \& Chan, T.C. (2010): Impact of an express admit unit on emergency department length of stay.J. Emerg. Med., 39(5):669-673.

Duogas, B. (1992): Principle patient care, comprehensive theory to nursing (1st ed.). Pub. by: Ministry of Health \& medical Education, Tehran. .

Ebrahimnia, M., Ameriun, A., Azizabadi Farahani, M. \& Khoddami Vishte, H. (2010): Satisfaction rate of hospitalized patients in military hospitals from presented services. Iran. J. Mili. Med., 12(2):101-105.

Faridpour, S., Feyzi, J.S. \& Aghlmand, S. (2015): A study on the healthcare service elements effects on patients satisfaction among the university social security and private hospitals in Urmia. J. Urmia Nurs. Midwifery Fac., 13(5):404-416

Fesharaki, M., Akbari, H., Akbari, H. \& Mohamadian, M. (2015): Inpatient Satisfaction and Effecting Factors: Findings from a Large Sample Size Cross Sectional Study. Health Res., 1(1):23-32.

Hall, M.F. \& Press, I. (1996): Keys to patient satisfaction in the emergency department: results of a multiple facility study. Hosp Health Serv Adm., 41(4):515-532.

Hesselink, G., Schoonhoven, L., Barach, P., Spijker, A., Gademan, P., Kalkman, C., Liefers, J., Vernooij-Dassen, M. \& Wollersheim, H. (2012): Improving patient handovers from hospital to primary care: a systematic review. Ann. Intern. Med., 157(6):417-28.

Hekkert, K.D., Cihangir, S., Kleefstra, S.M., van den Berg, B., Kool, R.B. (2009): Patient satisfaction revisited: a multilevel approach. Soc. Sci. Med., 69(1):68-75.

Horwitz, L.I., Moriarty, J.P., Chen, C., Fogerty, R.L., Brewster, U.C., Kanade, S., Ziaeian, B., Jenq, G.Y. \& Krumholz HM. (2013):
Quality of discharge practices and patient understanding at an academic medical center. $\lfloor A M A, 173(18): 1715-1722$.

Janati, A., Imani, A., Khanghah, H.A. \& Mosavi, M.H. (2016): Assessment of admission to discharge process in order to improve the patient satisfaction in Noornegat private hospital in Tabriz, 2014. Depiction Health, 6(3):8-15.

Kurpas, D. \& Steciwko, A. (2005): Patient satisfaction as the main indicator of primary care quality. Przegl. Lek., 62(12):1546-1551.

Lee, D.S., Tu, J.V., Chong, A. \& Alter, D.A. (2008): Patient satisfaction and its relationship with quality and outcomes of care after acute myocardial infarction. Circulation., 118(19):1938-1945.

Lin, P.C., Wang, J.L., Chang, S.Y. \& Yang, F.M. (2005): Effectiveness of a discharge-planning pilot program for orthopedic patients in Taiwan. Int. J. Nurs. Stud., 42(7):723-731.

Montazeri, A., Omidvari, A., Shahidzadeh, A., Azin, S.A., Harirchi, A.M., Soori, H., Jafari, H. \& Goodarzi, F (2008): Patient satisfaction with emergency departments. Payesh J., 7(2):141-152.

Narenjiha, M., Haghighat, S., Bahaddor, H., Shajari, J. \& Hoseini, H.M.F (2012): Patients' satisfaction from doctors' communication: a survey in Ghods clinic in Tehran. Iranian J. Med. Edu., 12(1):77-89.

Nerea, G., Quintana, J.M., Bilbao, A., Escobar, A., Aizpuru, F., Thompson, A., Esteban, C., Sebastián, J.A.S. \& de la Sierra, E. (2005): Development and validation of an in-patient satisfaction questionnaire. International $L$. Qual. Health Care, $17(6): 465-472$.

Omidvari, S., Shahidzadeh, A., Montazeri, A., Azin, S.A., Harirchi, A.M. \& Souri, H. (2008): Patient satisfaction survey in the hospitals of Tehran University of medical Sciences, Tehran, Iran. Paiesh Health Sci. J. Jehad Daneshgahi. 2:141-152.

Sadaghyani, E. (2005): Evaluation of healthcare and hospital standards (2nd ed.) Pub. by: Jafari publication, Tehran.

Sarvandi, S. \& Shahroodi, K. (2016): Assessing the patients' hospitalization and discharge processes based on Kaizen approach and multiple-criteria decision making (MCDM) in a hospital. L.Hosp., 15(3):83-93.

Shaw, C.D. \& Kalo, I., (2002): World Health Organization: A background for national quality policies in health systems. Pub. by: WHO Reg. Off. for Europe, Copenhagen.

Shaikhi, M.R. \& Javadi, A. (2004): Patients' satisfaction of medical services in Qazvin educational hospitals. J. Ghazvin Univ. Med.Sci., 7(5):62-66. [In Persian].

Shepperd, S., Lannin, N.A., Clemson, L.M., McCluskey, A., Cameron, I.D. \& Barras, S.L. (2013): Discharge planning from hospital to home. Cochrane Database Syst Rev., (1):CDooo313.

Vanaki, Z. \& Habibipour, B. (2008): The assessment of effect discharge planning on patients satisfaction. Sci. J. Hamadan Nurs. Midwifery Fac., 16(2):25-35.

Zahednezhad, H., Poursharifi, H. \& Babapour, J. (2012): Relationship betweeh health locus of control, slip memory and physician-patient relationship with adherence in type II diabetic patients. I. Shahid Sadoughi Uni. Med. Sci. 20(2):249-258.

Zohor, A. \& Piri, Z. (2003): Inpatient satisfaction to shahid akbarabadi hospital from delivery services. J. Res. Health Sci., 3(1):29-34.

Zolfaghari, B., Ovesi, S.H. \& Kabirie, B. (2005): How to control the quality of Provide health care of patient satisfaction in hospitals. Tebva Tazkiyeh. 4(57):35-43. 